\title{
Intelectuais viajantes: caminhos para uma história da educação na América Latina
}

\author{
Intellectual travelers: paths to a history of education in Latin America
}

\author{
Alexandra Lima da Silva \\ Professora da Faculdade de Educação \\ Programa de Pós-Graduação em Educação \\ Universidade do Estado do Rio de Janeiro \\ alexandralima1075@gmail.com
}

Resumo: Muitos viajantes deixaram por escrito impressões a respeito dos locais visitados. Este artigo tem como objetivo compreender os olhares de três viajantes latinoamericanos entre 1850-1920. Pretende-se defender que, em linhas gerais, os viajantes nascidos na Ibero-América viveram em meio aos debates e transformações empreendidas na passagem do século XIX para o século XX. Deste modo, foram selecionadas para a análise, as experiências do historiador brasileiro José Francisco da Rocha Pombo, bem como as trajetórias dos intelectuais argentinos Domingo Faustino Sarmiento, Florencio Varela e Juan Alberdi e dos chilenos José Abelardo Nuñez e Hugo Lea-Plaza. O trabalho procurar estabelecer os pontos de aproximação nos olhares construídos pelos mesmos em seus relatos de viagem em relação aos projetos de educação para a América Latina.

Palavras Chaves: Relatos de viagem, Intelectuais, Latino-americanos.
Abstract: Many travelers have written about the impressions of places visited. This article aims to analyze the views of three Latin American travelers between 1850 and 1920. It is intended to argue that, in general, these travelers born in Latin America lived in the midst of debates and transformations undertaken in the late nineteenth century and in the early twentieth century. Thus, we selected for analysis the experiences of Brazilian historian José Francisco da Rocha Pombo, and the lives of Argentine intellectuals Domingo Faustino Sarmiento, Florencio Varela and Juan Alberdi and of Chilean José Abelardo Núñez and Hugo Lea-Plaza. The paper aims at setting the points of approximation in visions constructed by them in their travel writings in relation to education projects for Latin America.

Keywords: Travelers, Travel Reports, Latin America. 
O presente artigo tem como objetivo refletir sobre a importância das viagens para determinados intelectuais preocupados com as questões em torno das causas da educação no continente latino-americano, entre os anos 1850-1920. Situar o movimento desses sujeitos que estavam circunscritos ao continente americano e viveram em diferentes temporalidades e espaços, mas vivenciaram o contato com diferentes culturas e tiveram como olhar primordial a dimensão da aprendizagem, é o foco de nossa discussão. Segundo Michel Serres, as viagens desses intelectuais “consistem numa tal mestiçagem”, que através do encontro com o outro, com a alteridade, torna-se essencial para o entendimento da condição do viajante em suas angústias e inquietações (SERRES , 1997: 60). Por meio dos contatos estabelecidos, novos saberes e espaços são desvendados, em um constante movimento de busca pelo conhecimento. Conforme salientado por Serres, as várias diferenças conhecidas e assimiladas durante as viagens trazem para casa novos gestos e usos, além de muitas outras aprendizagens "para fazer brilhar a liberdade de invenção, ou seja, de pensamento" (MIGNOT \& GONDRA, 2008: 9).

No presente estudo torna-se necessário atentar para três aspectos principais: a viagem, o viajante e os registros produzidos. Se por um lado, os significados das viagens são plurais, na mesma medida encontramos uma multiplicidade de estudos que se propõem a refletir sobre esta temática, sendo as abordagens circunscritas a diferentes áreas do conhecimento, o que evidencia a abrangência e o caráter interdisciplinar da temática. Tais trabalhos propõem a investigação do viajante andarilho e têm como fonte documental de análise registros diversos, tais como cartas, cartões postais, bilhetes de embarque, diários, notas, relatórios de viagem. Para Mignot e Gondra, trata-se de "relatos de espanto, admiração, respeito e esperança, evidenciando olhares de familiaridade e estranhamento" (2008: 9). Já Juan Pimentel destaca que "leer el mundo no es otra cosa que escribirlo; descifrarlo siempre ha significado verbalizarlo" (2003: 17), enfatizando a importância do escrito e do relato de viagem como forma de decifrar e compreender novos mundos e culturas.

Neste aspecto, remeto-me ao que Michel de Certeau pontuou a respeito dos ditos "relatos de espaço":

Todo relato é um relato de viagem - uma prática do espaço. A este título, tem a ver com as táticas cotidianas, faz parte delas, desde o abecedário da indicação espacial (“dobre à direita", "siga à esquerda”), esboço de um relato 
cuja consequência é a escrita pelos passos, até ao "noticiário" de cada dia (...) Essas aventuras narradas, que ao mesmo tempo produzem geografias de ações e derivam para os lugares comuns de uma ordem, não constituem somente um "suplemento" (...) De fato organizam as caminhadas. Fazem a viagem, antes ou enquanto os pés a executam (1994: 200).

O trabalho de Mary Louise Pratt, originalmente intitulado Imperial eyes: travel writing and transculturation ${ }^{1}$, analisa a literatura europeia de viagem e exploração e tem por objetivo mostrar como os livros de viagem escritos por sobre diferentes partes do mundo criaram, em grande medida, uma ordem imperial para os ditos europeus locais, que passaram a se sentir parte do projeto planetário do império. Para a autora, os livros de viagem tiveram amplo êxito, sobretudo porque forneceram aos leitores do velho mundo um sentido de propriedade e familiaridade com diferentes regiões colonizadas. Para a pesquisadora canadense, tais livros são concebidos como os geradores de sensações de curiosidade, emoção e aventura, pelo ânimo moral com relação ao expansionismo europeu, em uma dinâmica de poder e de apropriação (PRATT, 2010).

Segundo o pesquisador espanhol Juan Pimentel, se o telescópio e o microscópio possibilitaram novas faculdades para observar o distante e o diminuto, a viagem pode ser pensada como o outro grande instrumento capaz de ampliar o horizonte do saber (2003: 51). Os viajantes, por meio de relatos e descrições dos locais visitados, ajudariam na construção dos novos edifícios do saber, ocupando o papel de testemunhas do mundo (“testigos del mundo"). Repleto de fruição cosmopolita, o investimento nas publicações sobre viagens, na perspectiva de Pimentel, foi associado à expansão comercial e à popularização do saber (PIMENTEL, 2003: 249).

As viagens se intensificaram durante o século XVIII. Nesse período mais pessoas de diferentes grupos e classes sociais começaram a viajar e a escrever sobre sua própria experiência. Paralelamente, houve o desenvolvimento da infraestrutura para a realização das viagens com a construção de ruas e melhoramento dos transportes. Ademais, a demanda por informações sobre os países estrangeiros impulsionou a literatura de viagens no mercado de livro europeu. Durante o século XIX, as primeiras formas de turismo

\footnotetext{
${ }^{1}$ Publicado originalmente em inglês, no ano1992, ganhou edição no Brasil em 2005, pela EDUSC, com o título Os olhos do império: relatos de viagem e transculturação. No presente trabalho, utilizo a nova edição em castelhano, publicada em 2010 pelo Fondo de Cultura Económica, intitulado Ojos imperiales: literatura de viajes y transculturación.
} 
transformaram as atividades relacionadas ao viajar em um fenômeno de massas (MUSSER, 2011: 9).

Por seu turno, Peter J. Brenner defende que o viajar modificou-se com o tempo, assim como as escritas sobre esta experiência. Na Europa do século XVIII, a curiosidade e o espírito de aventura foram completados pelos mitos de educação. No caso dos viajantes dos tempos modernos, Brenner é bastante cético: duvida que alguém aprenda alguma coisa e se torne uma pessoa diferente a partir de uma viagem dentro deste contexto, sobretudo ao se considerar o que denomina de "turismo de massa" (BRENNER, 2011: 18).

Já Carlos Sánches Gonzáles mostra o impacto da cultura escrita na expansão atlântica europeia entre os séculos. Compreende que mais do que uma decisão pessoal, escrever sobre o vivido no "novo mundo" fez parte de uma obrigação imposta pelos governantes àqueles que participaram das empreitadas de "conquista" e representou uma via de informação essencial para o exercício de poder e controle (GONZALEZ SÁNCHES, 2007: 13). À época, descobrir era, acima de tudo, viajar (GONZALEZ SÁNCHES , 2007: 13).

No universo das ciências sociais, destaca-se o trabalho do sociólogo Octávio Ianni sobre o tema. Para Ianni, "a história dos povos está atravessada pela viagem, como realidade ou metáfora" concebendo que nas mais diferentes culturais e organizações humanas há o elemento viagem, “seja como modo de descobrir o 'outro', seja como modo de descobrir o 'eu'” (IANNI, 2000: 13).

Em geral, a viagem compreende vários significados e conotações, simultâneas, complementares ou mesmo contraditórias. São muitas as formas das viagens reais ou imaginárias, demarcando momentos ou épocas mais ou menos notáveis da vida de indivíduos, famílias, grupos, coletividades, povos, tribos, clãs, nações, nacionalidades, culturas e civilizações. São muitos os que buscam o desconhecido, a experiência insuspeitada, a surpresa da novidade, a tensão escondida nas outras formas de ser, sentir, agir, realizar, lutar, pensar ou imaginar (IANNI, 2000: 13).

No âmbito da historiografia nacional, destacam-se os trabalhos de Miriam Moreira Leite, dedicados aos estrangeiros que vieram para o Rio de Janeiro durante o século XIX. Para a autora "alguns desses livros são as correspondências dirigidas à família ou aos 
amigos; outros, diários de viagem, escritos sem a intenção de publicação, ou como apoio a um relatório posterior" (LEITE, 1997: 11).

Em Livros de viagem (1803-1900), Leite (1997) destaca o fato de o ser inferior o número de mulheres que registravam por escrito suas viagens, quando comparadas aos homens. Para a autora, tal desproporção se deve ao fato de que

A mulher viajante rompia alguns dos padrões mais incorporados e difundidos no século XIX - de condições de vida diferentes entre homens e mulheres. Não apenas a viagem é uma ampliação desmedida do espaço socialmente atribuído às mulheres, como aquelas que escrevem e publicam transgridem outros dois padrões aceitos para a vida feminina - que sejam caladas e sofridas e estabeleçam os elos entre as diferentes gerações da família de que fazem parte (LEITE, 1997: 100).

Nem sempre os viajantes eram do sexo masculino: muitas mulheres realizaram travessias pelo mundo.

Organizado por Sara Beatriz Guardia, o livro Viajeras entre dos mundos (2012) reúne estudos sobre mulheres viajantes de diferentes países da Europa e da América. No prefácio, a organizadora reflete:

Las viajeras son más que "testigos", son creadoras de una visión en clave femenina que trasciende el simple testimonio de la realidad que contemplaron. Este último aspecto de la visión de las viajeras, es uno de los objetivos de los estudios textuales sobre la capacidad de la palabra para transformar una realidad física en una realidad cognitiva e intelectual. Así considerados, los textos de viajeras son expresiones de la visión personal, social y generacional de las mujeres, espejos del proceso de cambio que experimentaron y del mundo que visitaron (GUARDIA, 2012: 9).

Angela de Castro Gomes escreveu o capítulo intitulado "A Grande Aliança, de Ana de Castro Osório: um projeto político-pedagógico luso-brasileiro" (2014), sobre a intelectual que, nascida em Portugal, em 1872, viajou para o Brasil em 1911, onde viveu até 1914. O trânsito da escritora objetivava estreitar o intercâmbio entre os dois países, em um projeto de circulação de livros entre as duas realidades. 
$\mathrm{Na}$ área de Letras, a tese de Claudete Daflon dos Santos investigou o papel que a viagem e a escrita desempenham no processo de formação e produção de alguns intelectuais brasileiros, entre finais do século XIX e as primeiras décadas do século XX. A autora defende que a viagem era privilégio dos ricos e bem-nascidos no período (SANTOS, 2002). Tal interpretação não é incorporada no presente artigo, uma vez que consideramos a possibilidade de a viagem ter sido uma prática realizada por intelectuais nascidos pobres e sem muitos recursos. Para muitos intelectuais, a viagem representou exatamente o contrário: um caminho para a sobrevivência no mundo das letras e do mercado editorial.

Em relação à categoria intelectual, remetemos ao campo aberto pela chamada História Intelectual, situada no cruzamento das Histórias Política, Social e Cultural. Dentre os estudos sobre "intelectuais", busco um diálogo mais estreito com as perspectivas teóricas de Jean-François Sirinelli, entendendo intelectuais em uma dupla acepção: uma mais ampla, como "criadores e mediadores culturais", e outra mais estreita, baseada na noção de "engajamento" (1996). Nesta perspectiva teórica, intelectuais são definidos como "produtores de bens simbólicos, mediadores culturais e atores do político" (SIRINELLI, 1996: 242), relativamente engajados na vida da cidade e/ou nos locais de produção e divulgação de conhecimento e promoção de debates.

Para o sociólogo francês Pierre Bourdieu, "a invenção do intelectual" teria se consumado com Émile Zola, não supondo apenas a autonomização prévia do campo intelectual, sendo este o resultado prévio de outro processo de diferenciação, "aquele que leva à constituição de um corpo de profissionais da política e exerce efeitos indiretos sobre a constituição do campo intelectual" (1996: 151). Enquanto um mundo à parte o campo intelectual seria um campo como os outros, onde as noções de poder e luta são cruciais. O campo intelectual (ou literário) é também um lugar de "relações de força (e de lutas que visam transformá-las ou conservá-las)" em torno de uma “espécie muito particular de capital", que é alvo das "lutas de concorrência" dentro do próprio campo, em que "o capital simbólico como capital de reconhecimento ou consagração

\footnotetext{
${ }^{2}$ Dentre as referências sobre a questão, destaco as contribuições dos estudos de Antonio Gramsci, para quem "todos os homens são intelectuais (...), mas nem todos os homens desempenham na sociedade a função de intelectuais” (p. 6), propondo também, uma distinção entre os diferentes tipos de intelectuais, sobretudo no que se refere às categorias orgânica e tradicional (GRAMSCI,1982). Outra referência central é o cientista político Norberto Bobbio, que concebe os intelectuais como "um conjunto de sujeitos específicos, considerados como criadores, portadores, transmissores de ideias, que desde há um século são normalmente chamados intelectuais" (BOBBIO, 1997: 109). Para Bobbio, questão a ser pensada sobre essa categoria seria o "problema da relação entre intelectuais- com tudo o que representam de ideias, opiniões, visões de mundo, programas de vida..." (BOBBIO,1997: 112).
} 
institucionalizada ou não, que os diferentes agentes e instituições conseguiram acumular no decorrer das lutas anteriores ao preço de um trabalho e estratégias específicas" (BOURDIEU, 1997: 170).

Os intelectuais reunidos nesse artigo atuaram como mediadores sociais. Em relação à noção de engajamento, posicionaram-se em defesa da instrução pública como um pilar na construção de uma nação moderna.

A viagem empreendida por um intelectual pode ser uma ação reveladora de suas redes de sociabilidade, apoio e prestígio, ou, ainda, uma estratégia na luta pela legitimação em meio a elas, em seus microclimas, tensões e clivagens no interior dos grupos. Com respeito ao entendimento da noção de legitimação, penso que se deve considerar os processos e modos de obtenção de uma legitimidade ou aprovação entre os membros de uma coletividade. Nesse sentido, conforme salienta Bourdieu, "o reconhecimento, marcado e garantido socialmente por todo um conjunto de sinais específicos de consagração que os pares/concorrentes concedem a cada um de seus membros, é função do valor distinto de seus produtos" (1983: 127).

Os estudos na área de História da educação vêm contribuindo significativamente para a reflexão acerca da relação entre viagens e formação, sob a perspectiva de sua importância para a formação docente, a circulação de modelos pedagógicos, a difusão de livros e teorias educacionais, enfim, para o intercâmbio e a troca de saberes e práticas pedagógicas. Nesse sentido, tais estudos têm contribuído para repensarmos as experiências dos sujeitos plurais, tais como professores, diretores de escola, inspetores, jornalistas, religiosos e políticos, que viajavam em prol das causas da instrução.

Ana Paula Barcelos Ribeiro da Silva é outra importante referência neste campo de estudos, sobretudo no que concerne ao intercâmbio e a circulação de ideais no período. A autora analisa a importância das trocas entre intelectuais da Argentina e do Brasil, para refletir acerca das discussões em relação à escrita da História (SILVA, 2011). Sinaliza, ainda, para a necessidade de uma problematização em torno do conceito de América Latina.

\section{Intelectuais e viagens em torno das causas da educação}

José Francisco da Rocha Pombo nasceu em 1857, na cidade de Morretes, interior do atual estado do Paraná. Ainda muito jovem, ingressou no magistério das primeiras 
letras e na escrita de periódicos, publicando artigos relacionados à instrução. Em 1897, mudou-se para o Rio de Janeiro, onde passou a frequentar os círculos intelectuais da capital, em esforços diversos para sobreviver e se estabelecer no campo intelectual. Foi poeta, contista, dicionarista, historiador, professor de História do Pedagogium, da Escola Normal, do Colégio Batista, membro do Instituto Histórico e Geográfico e jornalista. Faleceu aos 75 anos, quando acabara de ser eleito para a Academia Brasileira de Letras, sem conseguir tomar posse (SILVA, 2012: 12).

Defendo que a viagem empreendida em 1917 representou um divisor de águas na experiência de Rocha Pombo, estando, nesta ocasião, no auge de seus 60 anos, podendo ter representado a realização pessoal de uma vida, uma vez que desde muito nutria o desejo de visitar o norte, lamentando não ter sido possível fazê-lo antes de escrever a sua História do Brasil:

Desde muito nutria eu o desejo de visitar o norte. Lamento que me não fosse isso possível antes de escrever a minha História do Brasil. Tendo de resignarme as circunstancias que disso me privaram, só depois de concluído esse trabalho é que se proporcionou ensejo de realizar a minha velha aspiração (POMBO, 1918:8).

Ao adentrar pelo país, pôde conhecer pessoas, paisagens e histórias de um Brasil “interior" tão próximo e exótico ao mesmo tempo, remetendo, em muita medida, à dimensão proposta por Antonio Viñao, em relação à viagem, em que "todos los viajes educan, aunque solo sea por abrir al viajero a una realidad diferente a la suya. Sólo que unos educan más que otros, o de forma diferente a otros" (2007: 15). A dimensão da aprendizagem pode ser pensada enquanto um dos sentidos da viagem, mesmo quando esta não aparece como a motivação principal. Além disso, ao se percorrer o próprio país, o estranhamento do que seria familiar transforma o viajante, produzindo um olhar paradoxal, pois "ao mesmo tempo em que é estrangeiro em sua própria terra, é também um olhar nativo que busca reconhecer seus valores e sua história nos pequenos detalhes de sua viagem, construindo, assim, sua memória" (CABRAL, 2009: 5). A viagem é pensada aqui como uma prática social repleta de significados, também sob a concepção de representação, na acepção de Roger Chartier, entendida enquanto "esquemas intelectuais, que criam as figuras graças às quais o presente pode adquirir sentido, o outro tornar-se inteligível e o espaço ser decifrado" (1990: 17). 
$\mathrm{Na}$ diversidade de experiências em torno do viajar, destaca-se no presente artigo um conjunto de intelectuais nascidos na Ibero-América que embarcaram rumo ao exterior. O argentino Domingo Faustino Sarmiento ${ }^{3}$ foi enviado no ano de 1845 em missão oficial do governo chileno para estudar a formação de professores e métodos educativos na Europa. No período da viagem visitou Espanha, Itália, França e Prússia, onde analisou detalhadamente as políticas e realidades educacionais dos respectivos países Essa experiência lhe renderia muitos frutos: da publicação da obra De la educación popular (SARMIENTO, 1849) à aproximação com os estudos de M. Horace Mann, viajante norteamericano que desde 1843 vivia na Europa, estudando as distintas instituições educativas em países como Inglaterra, Irlanda, Escócia, nos territórios alemães, Holanda, Bélgica e França. As observações do intelectual argentino abarcaram um amplo espectro de estudos, desde os espaços e edifícios de ensino, as estruturas e sistemas educativos e métodos pedagógicos até as diferentes instituições educativas como escolas primárias, secundárias, normais, universidades, escolas públicas e privadas, reformatórios, dentre outras (SARMIENTO, 1849).

Assim como Sarmiento, outros dois argentinos viajaram para a Europa na primeira metade do século XIX. Aos 32 anos, Juan Bautista Alberdi chegou ao velho mundo em junho de 1843. Florêncio Varela, aos 36 anos, desembarcou em terras europeias em outubro do mesmo ano (WEINBERG,1997: 1006). Sarmiento, Alberdi e Varela tinham em comum o fato de viverem exilados, sendo que os dois últimos se encontravam no Uruguai. Com cinco meses de viagem, os destinos de Alberdi foram Itália, Suíça e França. Já Varela, com uma viagem de seis meses, dividia a sua estadia entre Inglaterra e França. Juan Bautista Alberdi ambicionava estudar o sistema judicial do reino da Sardenha, que considerava o mais adiantado da época, sendo sua viagem uma motivação pessoal e privada. Varela, por sua vez, foi comissionado pelo governo do Uruguai em missão diplomática junto ao governo da Inglaterra. Entretanto, outros interesses foram incorporados, como as atividades culturais e situação política dos países visitados (SARMIENTO 1997: 1009). Estes viajantes também produziram testemunhos escritos de suas experiências, como Veinte dias en Génova (1846), e Recuerdos de Europa (1844), de Alberdi, e Diario de viaje, de Varela, que permaneceu inédito até a década de 1970.

\footnotetext{
${ }^{3}$ Nascido em 1811, em San Juan, Argentina, foi opositor do regime político de Rosas, motivo que o levou ao exílio no Chile em 1841, onde permaneceu até 1853. Fundou a primeira Escola Normal de preceptoras da América do Sul no ano de 1845, e posteriormente, publicou uma de suas obras mais conhecidas, Facundo. Civilização e Barbárie. Vida de Juan Facundo Quiroga. Outra importante obra de Sarmiento deriva de suas travessias ao continente europeu. Cf: SARMIENTO 1997.
} 
Já o chileno José Abelardo Nuñez ${ }^{4}$ foi comissionado pelo Ministério de Justiça, Culto e Instrução Pública, no ano de 1878, para que estudasse na Europa e América o estado da instrução primária, para que informasse ao governo chileno acerca das instituições, regulamentos e demais elementos da organização que pudessem ser aplicados nas escolas da República chilena. De acordo com Alvaro Ceballos (2008), que a analisou as correspondências de Nuñez às autoridades do país, o intelectual permaneceu três anos e meio no exterior, onde afirmava ter cumprido tão importante comissão, tendo visitado os estabelecimentos de educação elementar, industrial e de ensino especial que lhes foram possíveis, destacando os Estados Unidos, Alemanha, Bélgica, Suécia, Noruega, Dinamarca e França (CEBALLOS, 2008: 43). José Abelardo Nuñez sugeriu que, para a aplicação dos progressos observados nos países estrangeiros nas escolas chilenas, as autoridades deveriam realizar visitas nas escolas da República (normais, superiores e primárias), de modo a tomar conhecimento do estado em que se encontravam. ${ }^{5}$

Já nas primeiras décadas do século XX, o médico e criminalista chileno Hugo Lea-Plaza (1891-1963) foi contratado para estudar os regimes carcerários no velho mundo, de modo que produzisse uma análise acerca do problema da criminalidade e delinquência no Chile, sobretudo entre crianças e jovens, o que lhe rendeu muitas conferências e trabalhos a respeito da temática investigada.

Na perspectiva da pesquisadora Gabriela Ossenbach Sauter, o modelo de Estado que surge na ibero-américa no pós-independência assume as competências educativas, em detrimento da Igreja Com isso, a sociedade se seculariza, o conceito de nação é afirmado e aparece uma classe média que encontra na educação um fator de ascensão social. Ao mesmo tempo, ainda que indiretamente, há uma contribuição para o progresso econômico, à medida em que se iniciam os processos de industrialização e diversificação produtiva. A educação assume um papel importante em tais realidades, sendo a integração de distintos grupos sociais, culturais e étnicos, bem como a criação de uma identidade nacional e a legitimação do poder do Estado seus pontos fulcrais (SAUTER, 2010). Ainda segundo Gabriela Ossenbach, a América Latina é parte de um espaço ocidental comum, em que se produziu ao longo do século XIX a emergência dos sistemas públicos de

\footnotetext{
${ }^{4}$ Educador e advogado, José Abelardo Núñez nasceu em 1840. Foi incorporado à Sociedade de Instrução Pública como diretor em 1866. Publicou Organización de escuelas normales, fruto da experiência da viagem realizada a países estrangeiros (CEBALLOS, 2008: 43).

${ }^{5}$ Correspondência enviado por José Abelardo Nuñez ao Sr. Ministro, José Eujenio Vergara, em 9 de agosto de 1882. (Reproduzida em: NUNEZ, 1883: 13-15).
} 
ensino, isto é, um conjunto de instituições de amplitude nacional destinadas a oferecer ao menos a instrução elementar ao conjunto dos habitantes de um território, cuja organização caberia ao Estado. Assim, a consolidação do Estado foi acompanhada pela criação dos sistemas educativos nacionais (SAUTER, 2010: 31).

Neste contexto, destacamos os intelectuais viajantes nascidos na América Latina, e que viveram entre meados do século XIX e as primeiras décadas do século XX, possuíam algumas motivações e preocupações em comum.

A viagem de Rocha Pombo, por exemplo, se deu no interior do Brasil, em uma excursão voltada à descoberta das pessoas comuns e culturas de seu país de nascimento, então ainda desconhecido. Já os vizinhos latino-americanos, olhavam para o exterior, com o intuito de aperfeiçoar e adaptar as ideias, modelos e experiências estudadas e observadas em suas viagens. No caso de José Abelardo Nuñez, este também sugere ao governo chileno que as visitas às escolas do país eram fundamentais para que o governo conhecesse a realidade das mesmas, a fim de operar as mudanças advindas dos progressos da viagem ao estrangeiro. A experiência de Rocha Pombo não contempla o fato de ter sido comissionado pelo governo brasileiro para excursionar ao exterior, como ocorreu em muitos dos casos dos viajantes latino-americanos. Todavia, mesmo com tantas diferenças, alguns pontos aproximam as experiências destes homens: realizavam viagens de estudo, formação e investigação, sendo a preocupação primordial as questões referentes às causas da instrução, bastante presente em alguns casos, em especial com destaque para os escritos do argentino Sarmiento, do chileno Nuñez e do brasileiro Rocha Pombo. O viajante brasileiro defendia que a instrução pública deveria ser uma das causas principais dos governos em todos os estados e não somente no norte do país.

Especificamente na obra $O$ grande problema, editada em 1900 pela Tipografia do Brasil, Rocha Pombo traça um plano de criação de um novo Instituto de Educação, sendo possível verificar os diferentes entendimentos do autor em relação às ideias de educação e instrução ${ }^{6}$. Para ele, instruir seria a consolidação da existência moral, em que "não são apenas as classes cultas que o reconhecem: nos lares mais humildes, onde o apoucamento

\footnotetext{
${ }^{6}$ No âmbito da historiografia da educação, estudos têm se debruçado sobre a distinção entre instruir e educar, na passagem do século XIX para o século XX, que se manifestava, sobretudo, nas ações voltadas às classes pobres, nas quais as instituições de ensino não deveriam apenas instruir, mas principalmente, educar, "incutindo normas de comportamento, hábitos e determinados valores culturais, em detrimento da cultura e dos valores das próprias camadas populares". Deste modo, “educar, no sentido de difundir valores morais e comportamentos, instruindo por meio da alfabetização e do ensino de ofícios artesanais ou agrícolas, seriam ações fundamentais para um Estado que necessitava manter hierarquias e distinções sociais em uma sociedade que implodia, tanto do ponto de vista de sua base - fim da escravidão - quanto em relação à grande complexidade social” (SCHUELER,1999: 55).
} 
das inteligências parece reduzir as aspirações, vamos encontrar a mesma ansiedade que põe em movimento as classes abastardas" (POMBO, 1900: 3). Já a educação seria algo mais amplo, atingindo as esferas privadas da vida, a família, sendo necessária a superação do seu caráter tão exclusivamente clássico e cerebral, então existente.

Assim como nos escritos da viagem ao norte, também na obra o Grande Problema Rocha Pombo explicita a preocupação com a instrução para o povo, sobretudo no sentido de "criar escolas, arrolar analfabetos, compelir os pais a ver na escola o templo para onde se devem voltar todas as inspirações do seu amor, toda a sua solicitude pela sorte dos filhos" (POMBO, 1900: 2), pois esta questão se manifestaria de maneira absoluta na consciência universal, sendo o caminho para a solução de todos os problemas de ordem social.

Rocha Pombo defende que as atenções deviam ser voltadas tanto para a escola atual, uma vez que estas seriam a fonte das desgraças, quanto para o trabalho, que deveria tornar independente cada chefe de família, habilitando o homem simples do povo a "sair da contingência a que o reduziram na vida moderna as complicações de natureza social" (1900: 2). Já as crianças pobres, necessitariam de instrução gratuita, ou seja, "precisam de ser preparadas para a vida pela solicitude do estado". Contudo, afirma que é preciso uma outra escola gratuita, pois as que se ofereceriam às crianças do povo apenas as inutilizariam, as preparariam para a miséria: "essa nova escravidão que o ensino atual não elimina, antes agrava e torna mais tremenda" (POMBO, 1900: 2). Agravaria ainda mais a situação das escolas gratuitas a existência de poucos mestres zelosos, que, pagos pelo governo, e amparados pela dita politicagem, "não ligam os mestres ao cumprimento do seu dever, ao desempenho da sua missão o destino da própria família" (POMBO, 1900: 4). Acrescenta que não seriam as camadas mais pobres da sociedade que, em regra, frequentariam os estabelecimentos de instrução superior, e sim os ricos, tendo em vista que aos desamparados dão-se institutos que lhes convenham.

Ainda em favor da causa da educação das crianças pobres e desvalidas, Rocha Pombo avalia que o governo deveria criar tantas novas escolas quantas fossem necessárias, a fim de recolher dos centros urbanos o grande número de crianças que se perderiam para a vida, para então estabelecer a obrigatoriedade do ensino, na qual “deveríamos incluir mesmo no nosso código o crime de abandonar uma criança aos azares da sorte, desprovida de todos os meios de se fazer um elemento de bem comum no futuro" (POMBO, 1900: 33). 
Em $O$ grande problema, a visão sobre a instrução pelo país afora é mais ácida e negativa que em 1917. Para Rocha Pombo, o problema da instrução pública nos estados só teria piorado, argumentando que "a república não teve tempo de cuidar disso. Em muitos estados é questão morta, da qual nem cogitam os politiqueiros [...] se não quando disfarçam com os interesses de pátria os bons negócios que andam fazendo" (1900: 44). Se seu relato sobre as escolas normais é suave, nos tempos da viagem, em 1917, acentua o fato de que, apesar de todas as capitais possuírem uma escola destinada a preparar para o magistério, os alunos sairiam destas escolas "tão professores como quando entraram, pois para Rocha Pombo para o intelectual paranaense, nem a organização, nem a disciplina, nem o regime, nem os programas, nem os processos didáticos, nada, em suma, se coaduna com os fins de semelhantes institutos" (POMBO, 1918: 46).

No relato de viagem, por outro lado, é possível vislumbrar a existência de diferentes experiências de instrução pelo país, para além da esfera da capital da República, tida como locus intelectual e vitrine do progresso e da modernidade. Nas visitas que realizou aos mais variados espaços e instituições, Rocha Pombo contou com a companhia de diretores da instrução pública, jornalistas, professores, sendo estes sujeitos determinantes para a atenta observação do viajante no que tange às análises sobre a instrução pelo Brasil afora, que, segundo sua perspectiva deveria atingir variados públicos, com finalidades e abordagens distintas.

Rocha Pombo defendia, sobretudo, que a questão da Instrução Popular era uma necessidade da educação para a formação do povo brasileiro, “em que não cessarei de dar testemunho, a instrução popular é objeto da preocupação e do esforço de todos os governos e de todas as populações" (POMBO, 1918: 102).

Ainda em relação ao problema da instrução, o intelectual José Abelardo Nuñez apreendeu os seguintes aspectos, a partir de suas viagens: preparação do professor, escolas normais; organização do ensino; ensino primário; escolas elementares; escolas especiais (para a aprendizagem de ofícios, colônias agrícolas penitenciárias para crianças delinquentes). Nuñez acreditava que, por meio de seus relatos, poderia contribuir com a grande obra de reforma necessária ao progresso da educação popular, iniciada com o patriótico propósito defendido pelo Congresso e pelo poder executivo da nação (1883: 18).

Em meio as viagens, Sarmiento escreveu uma obra dedicada às questões da instrução popular, que concebia concebida como obrigação de todo o governo, no sentido de garantir a educação às gerações futuras, já que não se poderia contemplar a todos os 
indivíduos do presente. A defesa do intelectual argentino em seus escritos era a da necessidade da educação para a adaptação ao trabalho, para o desenvolvimento e superação da pobreza e obscuridade nacional. Segundo Sarmiento, "nuestros esfuerzos deben ser mayores para educar completamente las jeneraciones próximas si se atiende si se atiende a otras condiciones desfavorables que ha producido la colonización española" (1849: 21).

A partir das observações tecidas ao longo das viagens, Sarmiento relacionou educação e moralidade. Para o intelectual argentino, bastaria atentar para o comportamento dos trabalhadores, os quais sabendo ler e escrever se vestiriam com mais asseio, possuindo mais ordem e método nas ações, não cometendo tantos crimes, quando comparados aos que não eram instruídos.

Por fim, o presente estudo procurou indicar a partir das trajetórias dos intelectuais viajantes, alguns olhares sobre a instrução e as propostas para a realidade e especificidade de cada país. Dentre os aspectos que os aproximam, podem ser citadas a escrita e a publicação dos testemunhos advindos das viagens. A preocupação com as causas da educação é o outro elo que os une e permite que tais vestígios sejam estudados e problematizados à luz das questões pensadas e discutidas no âmbito das pesquisas em História da Educação na América Latina.

\section{Fontes}

NUNEZ, José Abelardo (1883). Organización de escuelas normales. Informe presentado al señor ministro de instrucción pública de Chile. Santiago: Imprenta de la Librería Americana.

POMBO, José Francisco da Rocha (1918). Notas de viagem. Norte do Brasil. Rio de Janeiro: Benjamin de Águila editor. (1900). O grande problema (plano de um novo Instituto de Educação). Rio de Janeiro: Cia. Typ. do Brasil.

SARMIENTO, Domingo F. (1997). Viajes. Edición crítica de Javier Fernández. Madrid: ALLCA XX.

SARMIENTO, Domingo Faustino (1849). De la educación popular. Santiago: Imprenta de Julio Berlin i Compania.

\section{Referências Bibliográficas}

BOBBIO, Norberto (1997). Os intelectuais e o poder. São Paulo: Editora da Universidade Estadual Paulista. 
BOURDIEU, Pierre (1996). As regras da arte: gênese e estrutura do campo literário. São Paulo: Companhia das Letras.

(1987). Coisas ditas. São Paulo: Brasiliense. (1983). Sociologia. São Paulo: Ática.

BRENNER, Peter J. (2011). Does Travelling Matter? the impact of travel literature on european culture. In: MUSSER, Ricarda (ed.). El viaje y la precepción del otro: viajeros por la Península Ibérica y sus descripciones (siglos XVIII y XIX). Madrid: Iberoamericana, pp.11-22.

CABRAL, Shirley Aparecida Gomide (2009). Que viajar é este? Descoberta e reflexão em Viagem a Portugal, de José Saramago. Revista Crioula, n. 6, pp.1-11, nov.

CHARTIER, Roger (1998). As utilizações do objeto impresso. Portugal: Difel.

CEBALLOS, Alvaro (2008). Las empresas editoriales de José Abelardo Nuñez en Alemania, 1881-1905. História, vol I, n. 4, pp. 43-52.

CERTEAU, Michel de (1994). Relatos de espaço. In: CERTEAU, Michel de. A invenção do cotidiano: artes de fazer. Petrópolis, RJ: Vozes.

DIAS, Olívia Biasin (2007). Falla-se todas as línguas. Hospedagem, serviços e atrativos para os viajantes estrangeiros na Bahia oitocentista. Dissertação (Mestrado em História). Universidade Federal da Bahia, Salvador.

FLORES ROJAS, Jorge (2010). La infancia y las amenazas de una sociedad en crisis. In: FLORES ROJAS, Jorge. Historia de la infancia en el Chile republicano (18102010). Santiago, Chile: Ocho Libros.

GRAMSCI, Antonio (1982). Os intelectuais e a organização da cultura. Rio de Janeiro: Civilização Brasileira.

GOMES, Angela de Castro. A Grande (2014) Aliança, de Ana de Castro Osório: um projeto político-pedagógico luso-brasileiro. In: MAGALHÃES, Marcelo; ROCHA, Helenice; RIBEIRO, Jayme; CIAMBARELLA, Alessandra. Ensino de história: usos do passado, memória e mídia. Rio de Janeiro: FGV, pp.79-112.

GUARDIA, Sara Beatriz (Org) (2012). Viajeras entre dos mundos. Dourados: UFGD.

GONZALEZ SÁNCHES, Carlos (2007). Homo viator, homo scribens: cultura gráfica, información y gobierno en la expansión atlántica (siglos XV-XVIII). Madrid: Marcial Pons Historia.

LEITE, Miriam Moreira (1997). Livros de viagem (1803-1900). Rio de Janeiro: Editora UFRJ.

MIGNOT, Ana Chrystina Venancio \& GONDRA, José Gonçalves (Orgs.) (2008). Viagens Pedagógicas. São Paulo, Cortez.

MUSSER, Ricarda (Ed.) (2011). El viaje y la precepción del otro: viajeros por la Península Ibérica y sus descripciones (siglos XVIII y XIX). Madrid: Iberoamericana.

IANNI, Octávio (2000). A metáfora da viagem. In: IANNI, Octávio. Enigmas da modernidade-mundo. Rio de Janeiro: Civilização Brasileira.

PIMENTEL, Juan (2003). Testigos del mundo. Ciencia, literatura y viajes en la ilustración. Madrid: Marcial Pons.

PIRES, Mário Jorge (2001). Raízes do turismo no Brasil: hóspedes, hospedeiros e viajantes no século XIX. São Paulo: Manole.

PRATT, Mary Louise (2010). Ojos imperiales. Literatura de viajes y transculturación. México: FCE.

SANTOS, Claudete Daflon dos (2002). A viagem e a escrita: Uma reflexão sobre a importância da viagem na formação e produção intelectual dos escritores-viajantes brasileiros. Tese (Doutorado em Letras). Pontifícia Universidade Católica do Rio de Janeiro, Rio de Janeiro. 
SCARZANELLA, Eugenia Scarzanella \& SCHPUN, Mônica Raisa Schpun (Dir.) (2007). Sin fronteras: dialogos de mujeres y hombres entre America latina y Europa (Siglos XIX y XX). Madrid: Iberoamericana/Vervuert.

SAUTER, Gabriela Ossenbach (2010). Las relaciones entre el Estado y la educación en América Latina durante los siglos XIX y XX. Revista Docencia, n. 40, mayo, pp.2331.

SERRES, Michel (1997). O terceiro instruído. Lisboa: Instituto Piaget.

SILVA, Alexandra Lima da (2012). Escritas de viagem, escritas da história: estratégias de legitimação de Rocha Pombo no campo intelectual. Tese (Doutorado em Educação). Universidade do Estado do Rio de Janeiro, Rio de Janeiro.

SILVA, Ana Paula Barcelos Ribeiro da (2011). Diálogos sobre a escrita da História. Ibero-americanismo, catolicismo, (des) qualificação e alteridade no Brasil e na Argentina (1910-1940). Tese (Doutorado em História). Universidade Federal Fluminense, Niterói, RJ.

SIRINELLI, Jean-François (1996). Os intelectuais. In: RÉMOND, René. Por uma história política. Rio de Janeiro: Ed. UFRJ/Ed. FGV, pp.231-270.

WEINBERG, Félix (1997). Sarmiento, Alberdi, Varela: viajeros argentinos por Europa. In: SARMIENTO, Domingo F. Viajes. (Edición crítica de Javier Fernández). Madrid: ALLCA XX, pp.1005-1026.

WEINBERG, Felix. (1975). El Diario de viaje inédito de Florencio Varela por Inglaterra y Francia (1843-1844). Revista Histórica, t XLV, pp. 195-379.

16 Artigo recebido em 28 de março de 2015.

Aprovado em 10 de junho de 2015. 